\section{Erratic swimming}

\section{John J. Videler}

\section{Fish Locomotion.}

By R.W. Blake.

Cambridge University Press: 1983.

$$
\text { Pp.208. £29.50, \$57.50. }
$$

THE text on the jacket of Fish Locomotion tells of discussion of a wide variety of subjects to be found inside, from basic concepts to new developments in this area of research. The book is intended to survey and review some of the more important aspects in the field, and so to be of interest to students of fish biomechanics, functional morphology, behaviour and ecology. The detailed list of contents is promising, too, covering basic fluid dynamics, muscle physiology and morphology, kinematics and energetics of different modes of locomotion, as well as 'hot' topics such as optimal swimming strategies.

Alas, the book itself is very disappointing. The preface starts with the nebulous statement that Aristotle anticipated Newton by twenty centuries in recognizing the physical basis of the process of undulatory swimming. Such a statement irritates when there is no attempt to support it and this irritation does not vanish as one delves further into the book. I will direct my criticism to three aspects.

First there is the explanation of important concepts, several passages giving the impression that the author has an incomplete grasp of the theories he is attempting to elucidate. In the account of induced drag, for example, faulty trigonometric deduction is clearly caused by a slovenly drawing but also reveals a superficial understanding of the phenomenon. The explanation of Weihs' theory of the energetic advantages of burst and coast swimming is partly wrong and again shows a lack of understanding of the original paper.

The second fault is that, throughout the book, the literature is misquoted. For example, Rosen and Cornford (Nature $234,49 ; 1971)$ presented data on the ability of fish slimes to reduce friction of the water. They included one measurement of the nut brown Cowrie: a mollusc. Not only does Blake consistently refer to the authors as Rosen and Cornfield, but he describes the cowrie as " a very slow swimming fish". The time interval between the images of swimming plaice larvae (Figs 131, 132) based on a paper by Batty (1981) is not 0.028 but $0.014 \mathrm{~s}$.

Finally there are the figures and graphs, many of which show signs of carelessness. In 1933 Gray published a series of elegant and accurate drawings of cine pictures of swimming fish, and used them again in his 1968 book on animal locomotion. There are many more filmed records now available but Blake uses these pictures, modified in such an ugly way that it is hard to recognize the original drawings.

This book seems to have been written and produced under pressure, every aspect of it betraying haste. This is a great pity, for the subject deserved better.

John J. Videler is a Senior Lecturer in the Department of Zoology, Groningen State University, The Netherlands.

\section{Catch control}

\section{D.H. Cushing}

\section{Fish Stock Assessment: A Manual of}

Basic Methods.

By J.A. Gulland.

Wiley: 1983. Pp.236. f15.95, \$31.95.

JoHN Gulland is a statistician with great experience of the needs of fish stock managers; he is as familiar with computer programs as with the envelopes on which he did essential sums for two International Fisheries Commissions assessing fish stocks.

His discussion of the data required, on catch per unit of effort, on average catchability, fishing effort, fishing power and fishing intensity is the work of one with very great experience. There are good accounts on the problems in handling the material for production and analytic models, not so much in statistical arithmetic but in the approach to judgment. The manual is intended for tyros but the old hands should read it carefully for the insights revealed from sentence to sentence.

The stages in the development of a fishery are described and they show why assessment is needed. A most useful section on the maximum sustainable yield shows how the concept remains valuable although for statistical and economic reasons, yields short of that maximum are desirable.

There is an interesting account of the unit stock, a difficult concept because it may be a species (as in the Southern Bluefin tuna), a subpopulation or even a group of species (as in the groundfish of the Gulf of Thailand). This is because there are operational requirements as well as the more obvious biological bases; I would have laid a little more stress on the genetic evidence. Current problems of density dependence and of multispecies interactions are stated and possible lines of research indicated.

There is a fisheries science (including studies of migration, bioenergetics, stabilization of populations amongst others) broader than that of stock assessment. But Gulland's manual will be of great value to assessment biologists with the responsibility for giving advice each year to the managers.

D.H. Cushing is a retired fisheries biologist interested in fisheries science and stock assessment.

\section{Refined analytical methods}

\section{Peter Brookes}

Handbook of Polycyclic Aromatic

Hydrocarbons.

Edited by Alf Bjørseth.

Marcel Dekker; 1983. Pp.744. \$150.

TO THE organic chemist or student of chemical carcinogenesis the words polycyclic aromatic hydrocarbons conjure up visions of complex synthetic methods, many and varied metabolic pathways, intricate reactions with cellular macromolecules and potent biological effects both in vitro and in vivo. The present book mentions none of these things. What therefore is left on the subject to fill a book of over 700 pages? To seek an answer one would need to consult physical or analytical chemists, industrialists or environmentalists, for whom this volume is primarily intended as a source of detailed information on the wide range of techniques applicable to the qualitative and quantitative analysis of these compounds.

In this respect, the Handbook has no equal. The chapters on the use of highpressure liquid chromatography and spectrometric methods are particularly detailed and each is supplemented by about 200 references to the original literature. Gas chromatography/mass spectrometry are ideal analytical techniques and their power is well illustrated by application to coalderived products. A single column run on the polycyclic aromatic hydrocarbon fraction of solvent-refined coal enables about 100 compounds to be identified and their concentration estimated.

The ubiquitous distribution of polycyclic aromatic hydrocarbons in the environment as a result of fossil fuel combustion, and the potent carcinogenicity of several members of the series, makes it desirable to measure their concentration in the air, soil, sea, lakes and rivers. Since all food stuff must be in contact with one of these sources, the levels of these hydrocarbons in food are of some concern, and these natural levels may be increased by cooking and preserving. Suprisingly, although malting of barley involves exposure to the smoke from peat, the levels of polycyclic aromatic hydrocarbons found in whisky are extremely low.

The Handbook is nicely produced and has much of its information presented in clear tables and figures. Few people would wish to read the whole book but many more would find it a useful reference volume for facts, and at least an introduction to methodology.

Dr Peter Brookes is Reader in Chemistry of the University of London and Chairman of the Chemical Carcinogenesis Section, Institute of Cancer Research. 